\title{
Genetic Variability in the Saccharomyces Sensu Stricto Complex Revealed by Multilocus Enzyme Electrophoresis
}

\author{
KATARZYNA LEWICKA, ${ }^{*}$ MICHELE MALLIE, AND JEAN-MARIE BASTIDE \\ Laboratoire d'Immunologie et de Parasitologie, UFR des Sciences Pharmaceutiques, 34060 Montpellier Cedex, France
}

\begin{abstract}
Fifty-two strains of the genus Saccharomyces, including 50 yeasts of the Saccharomyces sensu stricto complex (sensu Vaughan Martini 1989 [A. Vaughan Martini, Syst. Appl. Microbiol. 12:119-122, 1989]), were analyzed for nine isozyme loci with starch gel electrophoresis. The genetic analysis of isozyme data provided further evidence that the Saccharomyces sensu stricto complex is a genetically heterogeneous group. Twenty-two different electrophoretic types were identified and could be grouped into four clusters. However, no correlation between these clusters and the currently defined species Saccharomyces cerevisiae, Saccharomyces bayanus, Saccharomyces pastorianus, and Saccharomyces paradoxus was detected. Several strains could not be assigned to their putative cluster.
\end{abstract}

The criteria used in traditional yeast taxonomy are not always satisfactory for differentiation of species, in part because many separations are based on the presence or absence of assimilative abilities, which are often controlled by single mutable genes (15). Vaughan Martini (45) differentiated several species within the Saccharomyces sensu stricto group, while Yarrow (52) considered these as a single species ( $S$. cerevisiae). This is a good example of this problem of strain variability in standard carbon assimilation and fermentation tests $(3,52)$. Other traditional methods also lead to ambiguous results (5).

Recently there have been several reports on the use of molecular techniques to distinguish between strains of the Saccharomyces sensu stricto group. These criteria include levels of rRNA and DNA relatedness $(16,36,46)$, electrophoretic whole-cell protein patterns (44), restriction endonuclease patterns $(17,22,28,30)$, and electrophoretic karyotyping $(23,31$, 49). Using DNA-DNA reassociation, Vaughan Martini et al. $(46,48)$ found that at least four species exist in the Saccharomyces sensu stricto complex: $S$. cerevisiae, $S$. bayanus, $S$. paradoxus, and $S$. pastorianus. This technique has been widely used to define species limits and relationships. However, it lacks the precision required for the analysis of genetic relationships among closely related strains (37). Analysis of whole-cell protein patterns and restriction enzyme analysis of genomic DNA or genes coding for rRNA were largely limited to differentiation of strains (12). Restriction enzyme analysis of mitochondrial DNA has given good results in the past $(6,22,34)$ but requires a large number of screenings in order to define a suitable restriction enzyme. Recently, Guillamon et al. (9) have differentiated among the four species with four restriction enzymes. However, their results were not statistically checked. Previous studies of karyotypes of Saccharomyces strains were not always able to differentiate between $S$. cerevisiae and $S$. bayanus $(13,23)$. In other cases, chromosome fingerprinting was able to provide a definitive fingerprint for every strain employed (5). This method is reliable but relatively complex and time-consuming and requires sophisticated and expensive equipment. Moreover, it does not permit analysis of a large number of samples. Thus, chromosome fingerprinting would be inappropriate for rapid identification of yeasts.

None of these techniques is fast and specific enough to

\footnotetext{
* Corresponding author. Mailing address: Laboratoire d'Immunologie et de Parasitologie, UFR des Sciences Pharmaceutiques, 15 av. C. Flahault, 34060 Montpellier Cedex, France.
}

differentiate strains. Multilocus enzyme electrophoresis (MLEE), which has long been a standard method in eucaryotic population genetics $(1,18,24,33,38)$ and systematics $(11,25)$, could be used in large-scale studies to estimate the genetic diversity in natural populations of a variety of yeast species. In the case of the systematics of Saccharomyces species, some promising studies have been done. These studies differentiated between several strains of the same species, but the strains of the Saccharomyces sensu stricto and/or enzymatic systems investigated were too limited $(10,41,51)$.

The present paper deals with the electrophoretic comparison of seven enzymes of Saccharomyces sensu stricto strains and discusses their relationships.

\section{MATERIALS AND METHODS}

Yeast strains. We studied 52 strains belonging to the genus Saccharomyces (Table 1). For clarity, species will be discussed according to the group divisions established in a recent study with partial rRNA sequence analysis of type strains (16). Accordingly, the genus can be divided into three groups: (i) Saccharomyces sensu stricto spp. (sensu Vaughan Martini 1989 [45]), which include $S$. bayanus, $S$. cerevisiae, S. paradoxus, and S. pastorianus; (ii) Saccharomyces sensu lato spp. (sensu Vaughan Martini 1988 [47]), comprising S. dairensis, S. castellii, S. exiguus, $S$. servazzii, and S. unisporus; and (iii) S. kluyveri.

Fifty strains were representatives of Saccharomyces sensu stricto spp. (52) Since it was important to include representatives of each species or group in a screening experiment, we used two genetically different species, $S$. kluyver (group 3) and S. servazzii (group 2), as controls. Moreover, at least one strain of each subgroup of Saccharomyces sensu stricto spp. was used.

The identity of the strains was confirmed by numerical analysis of sugar assimilation patterns with the commercial kit ID32C (BioMérieux, Marcy l'Etoile, France).

Enzyme extracts. All yeast cells were cultured on Sabouraud medium at $27^{\circ} \mathrm{C}$ for $48 \mathrm{~h}$. Cells were harvested by centrifugation at $1,000 \times g$ and $4^{\circ} \mathrm{C}$ for $10 \mathrm{~min}$, and then $1.6 \mathrm{~g}$ (wet weight) was suspended in approximately $1 \mathrm{ml}$ of distilled water. Yeast cells were disrupted in a Braun cell homogenizer with 0.25-mmdiameter glass beads. The mixture was then centrifuged at $12,000 \times g$ and $4^{\circ} \mathrm{C}$ for $5 \mathrm{~min}$. The supernatant was distributed into $150-\mu \mathrm{l}$ aliquots and stored at $-20^{\circ} \mathrm{C}$.

Electrophoresis and staining procedures. The enzymes (abbreviations in parentheses) studied were aspartate aminotransferase (Aat; EC 2.6.1.1), NADP $^{+}$ glutamate dehydrogenase ( $G d h$; EC 1.4.1.4 [coenzyme NADP]), glucose-6-phosphate dehydrogenase (G6pd; EC 1.1.1.49), glucose phosphate isomerase (Gpi; EC 5.3.1.9), isocitrate dehydrogenase (Idh; EC 1.1.1.42), malate dehydrogenase (Mdh; EC 1.1.1.37), and peptidase 1 (Pep 1; EC 3.4.11/13.- [substrate, L-valineL-leucine]).

Enzymes were separated by electrophoresis in a horizontal starch gel. Starch gel electrophoresis is relatively inexpensive and can be used to screen a large number of strains and many different enzyme activities simultaneously. The resolution by this technique is adequate for the detection of isozymes coded by different loci. Starch gels were prepared as described by Pasteur et al. (27), with $40 \mathrm{~g}$ of hydrolyzed starch (Sigma, S4501) suspended in $400 \mathrm{ml}$ of diluted electrophoresis buffer $(4,27)$. Staining was performed according to the methods of 
TABLE 1. Saccharomyces strains examined

\begin{tabular}{|c|c|c|c|c|c|}
\hline Strain (UM1 no.) & Original epithet ${ }^{a}$ & Other designation & Obtained from ${ }^{b}$ & Isolation source & ET \\
\hline 386 & S. carlsbergensis & & ENSAM & Unknown & 1 \\
\hline 1298 & S. carlsbergensis & ATCC 10596 & UM1 & Unknown & 1 \\
\hline 1642 & S. carlsbergensis & & IP & Unknown & 1 \\
\hline 4051 & $S$. cerevisiae & CBS 2354 & CBS & Grape must & 1 \\
\hline 7005 & S. carlsbergensis & & IP & Unknown & 1 \\
\hline 7023 & S. carlsbergensis & & ENSAM & Unknown & 1 \\
\hline 7015 & S. cerevisiae & & UL1 & Unknown & 2 \\
\hline 7018 & S. uvarum & & ENSAM & Unknown & 3 \\
\hline 7019 & S. uvarum & & ENSAM & Unknown & 3 \\
\hline 7022 & S. carlsbergensis & & ENSAM & Unknown & 3 \\
\hline 389 & S. cerevisiae var. ellipsoideus & & ENSAM & Unknown & 4 \\
\hline 842 & $S$ cerevisiae & CBS 2978 & UM1 & Distillery & 4 \\
\hline 1196 & S. cerevisiae & & ENSAM & Unknown & 4 \\
\hline 1197 & S. cerevisiae & & ENSAM & Unknown & 4 \\
\hline 1198 & S. cerevisiae & & ENSAM & Unknown & 4 \\
\hline 1295 & S. cerevisiae & CBS 2978 & ENSAM & Distillery & 4 \\
\hline 4056 & S. pastorianus & CBS 1539 & CBS & Grapes & 4 \\
\hline 7006 & S. cerevisiae & CBS 2978 & IP & Distillery & 4 \\
\hline 7007 & S. cerevisiae & & IP & Unknown & 4 \\
\hline 7010 & S. uvarum & CBS $395^{\mathrm{T}}$ & UL1 & Berries & 4 \\
\hline 7017 & S. cerevisiae & CBS 1512 & ENSAM & Unknown & 4 \\
\hline 840 & S. cerevisiae & CBS 1544 & UM1 & Fruit juice & 5 \\
\hline 7020 & S. cerevisiae & & ENSAM & Unknown & 5 \\
\hline 997 & S. cerevisiae & CBS $1171^{T}$ & UM1 & Beer (top yeast) & 6 \\
\hline 1000 & S. cerevisiae var. ellipsoideus & ATCC 560 & UM1 & Distillery & 6 \\
\hline 7014 & S. cerevisiae & CBS $1171^{\mathrm{T}}$ & UL1 & Beer (top yeast) & 6 \\
\hline 1152 & S. cerevisiae & & UM1 & Unknown & 7 \\
\hline 1153 & S. cerevisiae & & UM1 & Unknown & 7 \\
\hline 7009 & S. cerevisiae & & UL1 & Unknown & 7 \\
\hline 7012 & S. uvarum & & UL1 & Unknown & 8 \\
\hline 998 & S. cerevisiae & & UM1 & Unknown & 9 \\
\hline 1154 & S. cerevisiae & & UM1 & Unknown & 9 \\
\hline 1155 & S. cerevisiae & & UM1 & Unknown & 9 \\
\hline 7004 & S. cerevisiae & & IP & Unknown & 10 \\
\hline 7008 & S. cerevisiae & CBS 679 & IP & Unknown & 10 \\
\hline 4054 & S. pastorianus & CBS 1260 & CBS & Unknown & 11 \\
\hline 7021 & S. carlsbergensis & & ENSAM & Unknown & 12 \\
\hline 841 & S. cerevisiae & CBS 2980 & UM1 & Unknown & 13 \\
\hline 1195 & S. cerevisiae & & ENSAM & Unknown & 14 \\
\hline 999 & S. cerevisiae & ATCC 287 & UM1 & Lager beer & 15 \\
\hline 1755 & $S$. pastorianus & CBS $1513^{\mathrm{T}}$ & CBS & Beer & 16 \\
\hline 4055 & S. pastorianus & CBS $1538^{\mathrm{T}}$ & CBS & Beer & 17 \\
\hline 1753 & S. bayanus & CBS $380^{\mathrm{T}}$ & CBS & Beer & 18 \\
\hline 7013 & S. bayanus & CBS $380^{\mathrm{T}}$ & UL1 & Beer & 18 \\
\hline 4049 & S. bayanus & CBS 1604 & CBS & Berries & 19 \\
\hline 4050 & S. bayanus & CBS 7001 & CBS & Mesophylax adoperus & 19 \\
\hline 7011 & S. bayanus & & UL1 & Unknown & 19 \\
\hline 1754 & S. paradoxus & CBS $432^{\mathrm{T}}$ & CBS & Unknown & 20 \\
\hline 4052 & S. paradoxus & CBS 406 & CBS & Oak exudate & 20 \\
\hline 4053 & S. paradoxus & CBS 5829 & CBS & Soil & 20 \\
\hline 1640 & S. senvazzii & CBS $4311^{\mathrm{T}}$ & UM1 & Soil & 21 \\
\hline 1641 & S. kluyveri & CBS 4798 & UM1 & Unknown & 22 \\
\hline
\end{tabular}

a $S$. cerevisiae var. ellipsoideus is actually synonymous of $S$. cerevisiae, $S$. uvarum is synonymous of $S$. cerevisiae (2) or $S$. bayanus (22, 36), and $S$. carlsbergensis is actually a synonym of $S$. pastorianus.

${ }^{b}$ ATCC, American Type Culture Collection, Rockville, Md.; CBS, Centraalbureau voor Schimmelcultures, Delft, Holland; ENSAM, Ecole Nationale Supérieure d'Agronomie de Montpellier, P. Galzy, Laboratoire de Génétique Microbienne, ENSAM, France; IP, Institut Pasteur, Paris, France; UL1, J. Villard, Laboratoire de Mycologie Fondamentale et Appliquée aux Biotechnologies Industrielles, Université Lyon 1, France; UM1, J.-M. Bastide, Laboratoire d'Immunologie et de Parasitologie, Université Montpellier 1, France.

Pasteur et al. (27), Ben Abderrazak et al. (4), Shaw and Prasad (39), and Richardson et al. (35), with slight modifications.

Analysis of data. Comparison of the mobilities of the enzymes from different isolates was made visually against one another on the same gel slice. Because the net electrostatic charge, and hence the rate of migration of a protein during electrophoresis, is determined by its amino acid sequence, each band can be directly equated with an allele of a specific locus. Bands are numbered in order of decreasing anodal mobility.

Isolates were grouped into electrophoretic types (ETs) with identical multilocus genotypes (i.e., a combination of alleles at all the loci). Allelic frequencies were used to calculate genetic distances between pairs of ETs with the index proposed by Thorpe (42). Gregorius (8) and Katz and Goux (14) consider this method of calculating genetic distances to be the most appropriate method for analysis of electrophoretic data because it is the only one which satisfies the axioms characteristic of a metric distance. Furthermore, because the distribution of its estimator fits the normal distribution, we were able to statistically test the significance of distance between pairs of ETs. Dendrograms were derived from the distance matrices by using the unweighted pair-group method with arithmetic averages algorithm of Sneath and Sokal (40) as computed with the RESTSITE version 1.1 package $(21 \mathrm{a})$. 


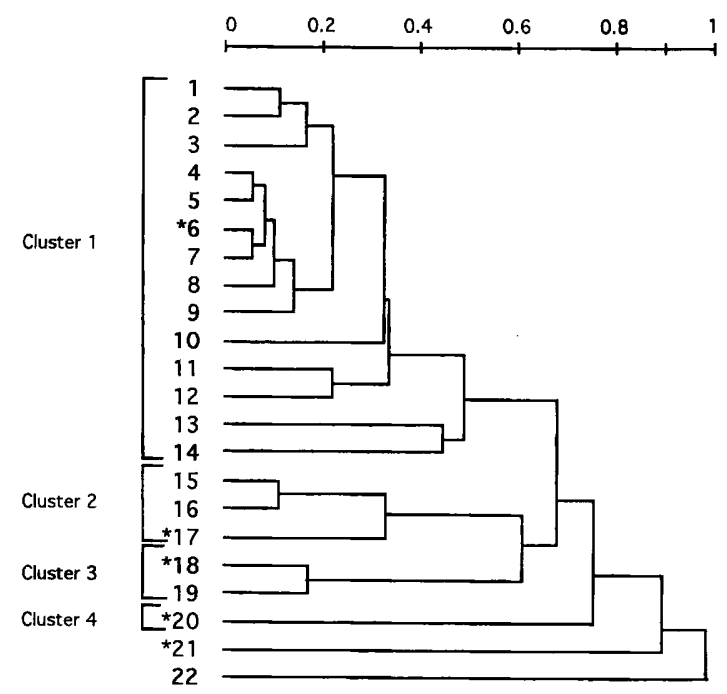

FIG. 1. Dendrogram of the 52 Saccharomyces strains, constructed by the unweighted pair-group method with arithmetic averages from a Gregorius distance matrix, obtained by MLEET. 1 to 22, ETs (see Table 1). ETs represent the following species (asterisks indicate type strains): S. bayanus, ETs * 18 and $19 ; S$. carlsbergensis, ETs 1, 3, and $12 ; S$. cerevisiae, ETs $1,2,4,5,{ }^{*} 6,7,9,10,13,14$, and $15 ;$ S. kluyveri, ET $22 ; S$. paradoxus, ET *20; S. pastorianus, ETs $4,11,16$, and * 17 ; S. servazzi, ET *21; S. uvarum, ETs 3, 4, and 8 .

In addition, several measures of intraspecific diversity were calculated. They included the percentage of polymorphic loci (i.e., number of loci having more than one variant divided by the total number of loci [7]) and the average number of alleles per locus. Genotypic diversity was calculated as the number of distinct ETs found in a species or population (37).

\section{RESULTS}

Overall genetic diversity. Isocitrate dehydrogenase and malate dehydrogenase activities were each expressed at two loci: $I d h-1$ and $I d h-2$ and $M d h-1$ and $M d h-2$. Locus 1 had the fastest electrophoretic migration, while the slower one was coded 2. Data were obtained for nine loci, all of which were polymorphic (polymorphic rate, 1.0), yielding 22 ETs: 12 of these were represented by only one strain. The overall genotypic diversity was 0.42 . The number of alleles per polymorphic locus ranged from 4 to 8 , with a mean of 5.1 per locus.

The genetic relationships among the Saccharomyces strains surveyed are represented in a dendrogram (Fig. 1). As expected, $S$. servazzii and $S$. kluyveri were separated from the Saccharomyces sensu stricto strains, with genetic distances of 0.896 and 0.985 , respectively. The remaining 50 strains fell into four distinct clusters. The distances separating the clusters were greater than 0.6 .

The first cluster is very heterogeneous. It includes all but one of the $S$. cerevisiae strains and also eight $S$. carlsbergenesis strains (UM1 386, 1298, 1642, 4051, 7005, 7021, 7022, and 7023), two $S$. cerevisiae var. ellipsoideus strains (UM1 389, and 1000 ), four $S$. uvarum strains (UM1 7010, 7012, 7018, and 7019), and two $S$. pastorianus strains (UM1 4054 and 4056). Because this cluster contains the type strain of $S$. cerevisiae $\left(\mathrm{UM} 1997=\mathrm{CBS} 1171^{\mathrm{T}}\right)$, it is designated $S$. cerevisiae. It includes two distinct subclusters (ETs 1, 2, and 3 and ETs 4 to 9). The overall isozyme patterns in each subcluster were similar: they differed by only one or two alleles. Two other $S$. pastorianus strains (UM1 1755 and 4055 ) and one $S$. cerevisiae strain (UM1 999) belong in the second cluster.

The five strains belonging to the third cluster (UM1 1753,
TABLE 2. Significance of the genetic distances between strains

\begin{tabular}{|c|c|c|c|}
\hline \multirow{2}{*}{ Location } & \multirow{2}{*}{$\begin{array}{c}\text { ET(s) } \\
\text { involved }\end{array}$} & \multicolumn{2}{|c|}{$\%$ of $:$} \\
\hline & & $\mathrm{S} / \mathrm{T}$ & $\mathrm{NS} / \mathrm{T}$ \\
\hline Inside $S$. cerevisiae cluster & $1,6,11,13$ & 13.3 & 86.7 \\
\hline $\begin{array}{l}\text { Between } S \text {. pastorianus and } \\
S \text {. cerevisiae cluster }\end{array}$ & $\begin{array}{l}15,17 \\
1,6,11,13\end{array}$ & 21.9 & 78.1 \\
\hline $\begin{array}{l}\text { Between } S \text {. bayanus and } \\
S . \text { cerevisiae cluster }\end{array}$ & $\begin{array}{l}19 \\
1,6,11,13\end{array}$ & 15.5 & 84.5 \\
\hline $\begin{array}{l}\text { Between } S \text {. paradoxus and } \\
S . \text { cerevisiae cluster }\end{array}$ & $\begin{array}{l}20 \\
1,6,11,13\end{array}$ & 24.4 & 75.6 \\
\hline
\end{tabular}

${ }^{a} \mathrm{~S}$, number of significant combinations in which given ETs were involved (i.e., when the two distances compared were significantly different from each other) NS, number of nonsignificant combinations in which given ETs were involved; T, total number of combinations in which given ETs were involved.

$4049,4050,7011$, and 7013) were all defined as S. bayanus. The fourth and last cluster included all of the $S$. paradoxus strains studied (UM1 1754, 4052, and 4053).

These three clusters are designated, respectively, $S$. pastorianus, $S$. bayanus, and $S$. paradoxus with regard to the type strains they include.

We have calculated the statistical significance of the genetic distances obtained among the eight strains selected in order to have one or more examples from each cluster. The comparisons were made on the one hand within the $S$. cerevisiae cluster and on the other hand between each cluster (as defined below) and the $S$. cerevisiae cluster. The results are regrouped in Table 2 . The data show that genetic distances between the four clusters are not statistically different. Therefore, these clusters or groups were just a nonrigorous representation of observed variances at the allelic level.

Genetic diversity in each group. For the four groups ( $S$. cerevisiae, $S$. bayanus, $S$. pastorianus, and $S$. paradoxus) the percentage of polymorphic loci, the mean number of alleles per locus, and the genotypic diversity were determined to estimate the relative diversity for each of them (Table 3). Results were not significantly different between them, except for the $S$. pastorianus group, but the number of strains studied was too small to be significant.

TABLE 3. Comparison of diversity values between Saccharomyces strains

\begin{tabular}{lrrrrr}
\hline \multicolumn{1}{c}{ Species or group } & $\begin{array}{c}\text { No. of } \\
\text { strains }\end{array}$ & ET & $\begin{array}{c}\text { Poly- } \\
\text { morphic } \\
\text { rate }^{a}\end{array}$ & $\begin{array}{c}\text { Mean } \\
\text { no. of } \\
\text { alleles/ } \\
\text { locus }\end{array}$ & $\begin{array}{c}\text { Genotypic } \\
\text { diversity }\end{array}$ \\
\hline $\begin{array}{l}\text { Saccharomyces spp. } \\
\text { Saccharomyces sensu }\end{array}$ & 52 & 22 & 1.00 & 5.10 & 0.42 \\
$\quad$ stricto group & 50 & 20 & 1.00 & 3.44 & 0.40 \\
S. cerevisiae & 39 & 14 & 1.00 & 2.67 & 0.36 \\
S. bayanus & 5 & 2 & 0.22 & 1.22 & 0.40 \\
S. paradoxus & 3 & 1 & 0.00 & 1.00 & 0.33 \\
S. pastorianus & 3 & 3 & 0.44 & 1.78 & 1.00 \\
\hline
\end{tabular}

${ }^{a}$ Polymorphic rate, number of loci having more than one variant divided by the total number of loci (7).

${ }^{b}$ Genotypic diversity, number of distinct ETs found in a species or population (37). 


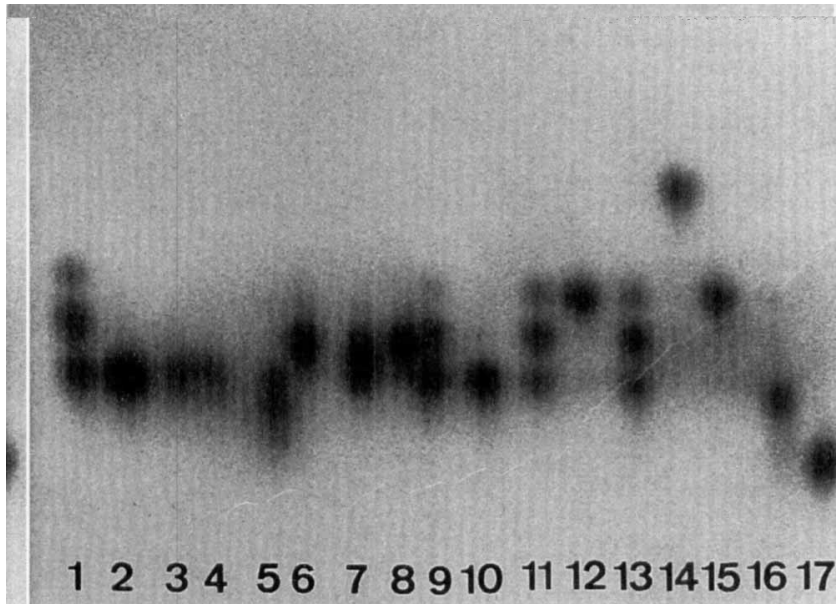

FIG. 2. Isozyme variation in various Saccharomyces strains for the enzyme glucose phosphate isomerase. Lanes: 1, 10, and 17, S. uvarum 7012 (ET 8), 7010 (ET 4), and 7018 (ET 3), respectively; 2 and 13, S. carlsbergensis 386 (ET 1) and 7021 (ET 12); 3, 5, 6, 7, 8, and 9, S. cerevisiae 1000 (ET 6), 998 (ET 9), 1152 (ET 7), 1154 (ET 9), and 7004 (ET 10); 4, $S$. paradoxus 1754 (ET 20); 11 and 16, $S$. pastorianus 4054 (ET 11) and 4056 (ET 4); 12 and 15, S. bayanus 1753 (ET 18) and 7011 (ET 19); and 14, S. servazzi 1640 (ET 21). Several three-banded patterns are seen, which suggests that this enzyme has a dimeric structure and that the corresponding strains are heterozygous for this locus.

\section{DISCUSSION}

The genetic interpretation of banding patterns was consistent with that of diploid organisms. The commonly accepted notion of $S$. cerevisiae as a diploid is supported by the observation of typical heterozygous patterns in the enzyme assays (Fig. 2). However, some strains should be aneuploids (31). In particular, the UM1 $1753^{\mathrm{T}}$ and $7013^{\mathrm{T}}$ (CBS $380^{\mathrm{T}}$ ) strains have been claimed to be trisomic aneuploids (13). However, this aneuploidy didn't appear in the isoenzymatic patterns studied and probably involves loci other than the ones studied by us.

The results obtained by MLEE were reproducible: enzyme extracts obtained at different times from separate cultures of the same strain showed the same profiles.

Our analysis of isozyme polymorphism provided further evidence that $S$. cerevisiae Meyen ex. Hansen (also referred to as Saccharomyces sensu stricto spp. [20]) represents a genetically heterogeneous group that is different from two other species of the genus Saccharomyces, $S$. kluyveri and $S$. servazzii.

The four clusters observed on the dendrogram (Fig. 1) were referred to as $S$. cerevisiae, $S$. bayanus, $S$. pastorianus, and $S$. paradoxus in relation to the type strains that were included. In the first cluster ( $S$. cerevisiae cluster), no correlation was observed between the different subclusters and denominations of the strains ( $S$. cerevisiae, $S$. cerevisiae var. ellipsoideus, $S$. uvarum, and $S$. carlsbergensis), described previously as different species (before their inclusion in the new circumscribed $S$. cerevisiae species [3]). Moreover, some strains previously described as belonging to other groups turned up in the $S$. cerevisiae cluster. These were $S$. uvarum strains (UM1 7010, 7012, 7018 , and 7019), which were previously described as synonymous with $S$. bayanus $(22,36)$, although Barnett et al. (3) placed them in synonymy with $S$. cerevisiae. Brewing lager strains (5) were also described under different epithets: $S$. cerevisiae (uvarum) (20), S. cerevisiae var. uvarum (Casey), or $S$. uvarum (carlsbergensis) (26). Thus, the designation of $S$. uvarum strains was not precisely defined. Another possibility is that the designation of these strains was based on the assimilation of melibiose. S. uvarum strains are considered to be able
TABLE 4. Multilocus genotypes of the 52 Saccharomyces strains identified with nine polymorphic loci

\begin{tabular}{lllllllllll}
\hline & \multicolumn{7}{c}{ ET $^{a}$} & \multicolumn{7}{c}{ Allele(s) shared } \\
\cline { 2 - 9 } & Aat & G6pd & Gdh & Gpi & Idh-1 & Idh-2 & Mdh-1 & Mdh-2 & Pep I \\
\hline 1 & 5 & 5 & 2 & 4 & 2 & 3 & 3 & 4 & 5 \\
2 & 5 & 7 & 2 & 4 & 2 & 3 & 3 & 4 & 5 \\
3 & 5 & 5 & 2 & 5 & 2 & 3 & 3 & 4 & 5 \\
4 & 5 & 6 & 2 & 4 & 2 & 3 & 3 & 4 & 5 \\
5 & 5 & 6 & 2 & 4 & 2 & 3 & 3 & 4 & $4 / 5^{c}$ \\
6 & 5 & 6 & 2 & $4 / 5$ & 2 & 3 & 3 & 4 & 5 \\
7 & 5 & 6 & 2 & $3 / 4$ & 2 & 3 & 3 & 4 & 5 \\
8 & 5 & 6 & 2 & $2 / 4$ & 2 & 3 & 3 & 4 & $4 / 5$ \\
9 & 5 & 6 & 2 & 3 & 2 & 3 & 3 & 4 & 5 \\
10 & 5 & $6 / 8$ & 3 & $2 / 4$ & 2 & 3 & 3 & 4 & $3 / 5$ \\
11 & 5 & $6 / 8$ & 2 & $2 / 4$ & 4 & 3 & 3 & 3 & 5 \\
12 & 5 & $6 / 8$ & 2 & $2 / 4$ & 3 & 3 & 3 & 4 & 5 \\
13 & 2 & 6 & 3 & 4 & 2 & 4 & 3 & 4 & 5 \\
14 & 5 & 2 & 3 & 4 & 2 & 3 & 3 & 4 & 5 \\
15 & 4 & $6 / 8$ & 2 & $2 / 4$ & 3 & 3 & 3 & 2 & 4 \\
16 & 4 & $6 / 8$ & 3 & $2 / 4$ & 3 & 3 & 3 & 2 & 4 \\
17 & 4 & $6 / 8$ & 2 & 2 & 0 & 3 & 3 & 3 & 4 \\
18 & 4 & 8 & 3 & 2 & 4 & 3 & 2 & 4 & $3 / 4$ \\
19 & 4 & 4 & 3 & 2 & 4 & 3 & 2 & 4 & 3 \\
20 & 3 & 7 & $3 / 4$ & 4 & 2 & 4 & 3 & 5 & 4 \\
21 & 3 & $4 / 6$ & 4 & 1 & 5 & 1 & 4 & 6 & 2 \\
22 & 1 & $1 / 3$ & 1 & 2 & 1 & 2 & 1 & 1 & 1 \\
\hline
\end{tabular}

${ }^{a}$ ETs are ordered as in Fig. 1.

${ }^{b}$ Note that 0 means the lack of activity for enzyme under study, but it has been interpreted as an allele quite different from the alleles observed.

${ }^{c}$ Homozygotes $\mathrm{a} / \mathrm{a}$ are noted as $\mathrm{a}$; heterozygotes are noted as $\mathrm{a} / \mathrm{b}$.

to assimilate this sugar, although some reports have shown that other Saccharomyces sensu stricto species can be $\mathrm{Mel}^{+}(23$, 43).

The other strains that turned up in the $S$. cerevisiae cluster were $S$. carlsbergensis strains (UM1 386, 1298, 1642, 4051, 7005, 7021, 7022, and 7023) and $S$. pastorianus strains (UM1 4054 and 4056). The UM1 4056 strain was described as belonging to the $S$. cerevisiae cluster (12), while UM1 4054, previously described as $S$. carlsbergensis, was later included in the $S$. pastorianus group (43). However, in earlier studies (52), $S$. carlsbergensis and $S$. pastorianus were both considered to be synonyms of $S$. cerevisiae.

The $S$. pastorianus cluster includes one $S$. cerevisiae strain (UM1 $999=$ ATCC 287), described as a lager beer yeast strain by the American Type Culture Collection. It could be related to $S$. carlsbergensis and $S$. pastorianus strains, according to Pedersen (29). However, Pedersen $(30,31)$ later demonstrated that lager beer strains ( $S$. carlsbergensis) were genetically distant from $S$. uvarum. Furthermore, other lager beer strains were included in the $S$. cerevisiae cluster (described above). The taxonomic status of $S$. uvarum strains remains unresolved.

The genetic distances observed between the four clusters were considerable $(>0.6)$. However, they were not statistically different, and the observed clusters could not be regarded as distinct species on the basis of these results. This is partly because the enzymes studied here involve only a small fraction of the genome (approximately 30\% [21]). Moreover, it could be caused by the low number of loci analyzed, particularly in view of the fact that five of nine loci $(G d h, I d h-1, I d h-2, M d h-1$, and $M d h-2)$ shared one or two of the same alleles. Nevertheless, the observed groups remain quite different with regard to their multilocus genotypes (Table 4).

The confrontation between strain designations and observed clusters showed that many of the original strain designations 
were not exactly correct, as observed by other authors $(12,30$, $31,43)$. This is due to the fact that the genus Saccharomyces has been frequently revised with respect to the composition of its members, and numerous species have been reclassified as synonyms (2). The realization that a single gene can confer on a yeast the ability to ferment or assimilate a sugar $(19,50)$ raises the possibility that species might be inadvertently and artificially established simply on the basis of the function of one or a few genes (32).

Because of the difficulty in increasing the number of loci analyzed, MLEE may not be a useful tool for the taxonomy of the Saccharomyces sensu stricto group. However, this method has an advantage compared with other methods in that it could be used in large-scale studies for the estimation of the genetic diversity and structure within natural populations or species of the Saccharomyces sensu stricto group and other species. A second goal of MLEE study is to identify a number of isozymes and their coding alleles unique to each group of isolates that can be used for identification. It seems that allele 2 of $M d h-1$ is characteristic of the $S$. bayanus group, but further analysis with a larger number of strains and loci is needed.

\section{ACKNOWLEDGMENTS}

We thank P. Galzy, S. Jouvert, J. Villard, and Institut Pasteur (Paris) for kindly providing yeast strains and $\mathrm{D}$. Castel for technical assistance. Special thanks go to C. Pujol and F. Renaud for helpful discussions.

\section{REFERENCES}

1. Ayala, F. J. (ed.). 1976. Molecular evolution. Sinauer Associates, Sunderland, Mass.

2. Barnett, J. A. 1992. The taxonomy of the genus Saccharomyces Meyen ex Rees: a short review for non-taxonomists. Yeast 8:1-23.

3. Barnett, J. A., R. Payne, and D. Yarrow. 1990. Yeasts: characteristics and identification, 2nd ed., p. 595. Cambridge University Press, Cambridge.

4. Ben Abderrazak, S., F. Guerrini, F. Mathieu-Daudé, P. Truc, K. Neubauer, K. Lewicka, C. Barnabé, and M. Tibayrenc. 1993. Isoenzyme electrophoresis for parasite characterization. Methods Mol. Biol. 21:361-382.

5. Casey, G. P., A. T. Pringle, and P. A. Erdmann. 1990. Evaluation of recent techniques used to identify individual strains of Saccharomyces yeasts. Am. Soc. Brew. Chem. 48:100-106.

6. Dubourdieu, D., A. Sokol, J. Zucca, P. Thalouarn, A. Dattee, and M. Aigle. 1987. Identification des souches de levures isolées de vins par l'analyse de leur ADN mitochondrial. Connaiss. Vigne Vin 21:267-278.

7. Galvan, S. C., J. Rubio, R. Sanchez, J. Ortega, and M. Castañeda. 1983. Phenetic variation in Trypanosoma (Schizotrypanum) cruzi isolates. Comp. Biochem. Physiol. 74B:573-578.

8. Gregorius, H. 1984. An unique genetic distance. Biom. J. 26:13-18.

9. Guillamon, J. M., E. Barrio, T. Huerta, and A. Querol. 1994. Rapid characterization of four species of the Saccharomyces sensu stricto complex according to mitochondrial DNA patterns. Int. J. Syst. Bacteriol. 44:708-714.

10. Hara, N., K. Saito, and T. Suto. 1985. Availability of isozyme patterns for identification of yeasts. Bull. Nippon Vet. Zootech. Coll. 34:221-233.

11. Holzschu, D. L., H. J. Phaff, J. Tredick, and D. Hedgecock. 1983. Pichia pseudocactophila, a new species of yeast occurring in necrotic tissues of columnar cacti in the North American Sonoran desert. Can. J. Microbiol. 29:1314-1322

12. Huffman, J. L., F. I. Molina, and S.-C. Jong. 1992. Authentication of ATCC strains in the Saccharomyces cerevisiae complex by PCR fingerprinting. Exp. Mycol. 16:316-319.

13. Kaneko, Y., and I. Banno. 1991. Reexamination of Saccharomyces bayanus strains by DNA-DNA hybridization and electrophoretic karyotyping. IFO Res. Commun. 15:30-41.

14. Katz, M., and J. M. Goux. 1986. The statistical properties of genetic absolute distance. Biom. J. 28:63-67.

15. Kurtzman, C. P., H. J. Phaff, and S. A. Meyer. 1983. Nucleic acid relatedness among yeasts, p. 139-166. In J. F. T. Spencer, D. M. Spencer, and A. R. W. Smith (ed.), Yeast genetics-fundamental and applied aspects. SpringerVerlag, New York.

16. Kurtzman, C. P., and C. J. Robnett. 1991. Phylogenetic relationships among species of Saccharomyces, Schizosaccharomyces, Debaryomyces, and Schwan- niomyces determined from partial ribosomal RNA sequences. Yeast 7:61-72.

17. Lee, S. Y., and F. B. Knudsen. 1985. Differentiation of brewery yeast strains by restriction endonuclease analysis of their mitochondrial DNA. J. Inst. Brew. 91:169-173.

18. Lewontin, R. C. 1974 . The genetic basis of evolutionary change. Columbia University Press, New York.

19. Lindergren, C. C., and G. Lindergren. 1949. Unusual gene-controlled combinations of carbohydrate fermentations in yeast hybrids. Proc. Natl. Acad. Sci. USA 82:6955-6959.

20. Lodder, J. (ed.). 1970. The yeasts-taxonomic study. North Holland, Amsterdam.

21. Marshall, D. R., and A. H. D. Brown. 1975. The charge-state model of protein polymorphism in natural populations. J. Mol. Ecol. 6:149-163.

21a.Miller, J. C. 1990 . RESTSITE, version 1.1 package.

22. Molina, F. I., T. Inoue, and S.-C. Jong. 1992. Ribosomal DNA restriction analysis reveals genetic heterogeneity in Saccharomyces cerevisiae Meyen ex Hansen. Int. J. Syst. Bacteriol. 42:499-502.

23. Naumov, G., E. Naumova, and C. Gaillardin. 1993. Genetic and karyotypic identification of wine Saccharomyces bayanus yeasts isolated in France and Italy. Syst. Appl. Microbiol. 16:274-279.

24. Nevo, E., A. Beiles, and R. Ben Shlomo. 1980. The evolutionary significance of genetic diversity: ecological, demographic and life history correlates. Lect Notes Biomath. 53:13-213.

25. Oxford, G. S., and D. Rollinson (ed.). 1983. Protein polymorphism: adaptative and taxonomic significance. The Systematics Association special volume no. 24. Academic Press, Inc., Ltd., London.

26. Panchal, C. J., L. Bast, T. Dowhanick, and G. G. Stewart. 1987. A rapid, simple and reliable method of differentiating brewing yeast strains based on DNA restriction patterns. J. Inst. Brew. 93:325-327.

27. Pasteur, N., G. Pasteur, F. Bonhomme, J. Catalan, and J. Britton-Davidian. 1987. Manuel technique de génétique par électrophorèse des protéines. Technique et Documentation Lavoisier, Paris.

28. Pedersen, M. B. 1983 . DNA sequence polymorphism in the genus Saccharomyces. I. Comparison of the HIS4 and the ribosomal RNA genes in lager strains, ale strains and various species. Carlsberg Res. Commun. 48:485-503.

29. Pedersen, M. B. 1985. DNA sequence polymorphism in the genus Saccharomyces II. Analysis of the genes RDN1, HIS4, LEU2 and Ty transposable elements in Carlsberg, Tuborg and 22 Bavarian strains. Carlsberg Res. Commun, 50:263-272.

30. Pedersen, M. B. 1986 . DNA sequence polymorphism in the genus Saccharomyces. III. Restriction endonuclease pattern of chromosomal regions in brewing and other yeast strains. Carlsberg. Res. Commun. 51:163-183.

31. Pedersen, M. B. 1986. DNA sequence polymorphism in the genus Saccharomyces. IV. Homologous chromosomes III of Saccharomyces bayanus, $S$ carlsbergensis and S. uvarum. Carlsberg. Res. Commun. 51:185-202.

32. Price, C. W., G. B. Fuson, and H. J. Phaff. 1978. Genome comparison in yeast systematics: delimitation of species within the genera Schwanniomyces, Saccharomyces, Debaryomyces, and Pichia. Microbiol. Rev. 42:161-193.

33. Pujol, C., J. Reynes, F. Renaud, M. Mallié, and J. M. Bastide. 1993. Analyse génétique des souches de Candida albicans par électrophorèse des isoenzymes. J. Mycol. Méd. 3:14-19.

34. Querol, A., E. Barrio, and D. Ramon. 1992. A comparative study of different methods of yeast strain characterization. Syst. Appl. Microbiol. 15:439-446.

35. Richardson, B. J., P. R. Baverstock, and M. Adams. 1986. Allozyme electrophoresis. A handbook for animal systematics and population studies. Academic Press, London.

36. Rosini, G., F. Federici, A. Vaughan Martini, and A. Martini. 1982. Systematics of the species of the yeast genus Saccharomyces associated with the fermentation industry. Eur. J. Appl. Microbiol. Biotechnol. 15:188-193.

37. Selander, R. K., D. A. Caugant, T. Ochman, J. M. Musser, M. N. Gilmour, and T. S. Whittam. 1986. Methods of multilocus enzyme electrophoresis for bacterial population genetics and systematics. Appl. Environ. Microbiol. 51:873-884.

38. Selander, R. K., and T. S. Whittam. 1983. Protein polymorphism and the genetic structure of populations, p. 89-114. In M. Nei and R. K. Koehn (ed.), Evolution of genes and proteins. Sinauer Associates, Sunderland, Mass.

39. Shaw, C. R., and R. Prasad. 1970. Starch gel electrophoresis of enzymes-a compilation of recipes. Biochem. Genet. 4:297-320.

40. Sneath, P. H. A., and R. R. Sokal. 1973. Numerical taxonomy. W. H. Freeman and Co., San Francisco.

41. Subden, R. E., D. Irwin, J. D. Cunningham, and A. G. Meiering. 1982. Wine yeasts isozymes. I. Genetic differences in 18 stock cultures. Can. J. Microbiol. 28:1047-1050.

42. Thorpe, J. P. 1979. Enzyme variation and taxonomy: the estimation of sampling error in measurements of interspecific genetic similarity. Biol. $\mathbf{J}$. Linn. Soc. 11:369-386.

43. Turakainen, H., S. Aho, and M. Korhola. 1993. $M E L$ gene polymorphism in the genus Saccharomyces. Appl. Environ. Microbiol. 59:2622-2630.

44. Van Vuren, H. J., and L. Van der Meer. 1988. Characterization of brewing yeast strains by numerical analysis of total soluble cell protein patterns. J. Inst. Brew. 94:245-248. 
45. Vaughan Martini, A. 1989. Saccharomyces paradoxus comb. nov., a newly separated species of the Saccharomyces sensu stricto complex based upon nDNA/nDNA homologies. Syst. Appl. Microbiol. 12:119-122.

46. Vaughan Martini, A., and C. P. Kurtzman. 1985. Deoxyribonucleic acid relatedness among species of the genus Saccharomyces sensu stricto. Int. J. Syst. Bacteriol. 35:508-511.

47. Vaughan Martini, A., and C. P. Kurtzman. 1988. Deoxyribonucleic acid relatedness among species of Saccharomyces sensu lato. Mycologia 80:241243.

48. Vaughan Martini, A., and A. Martini. 1987. Three newly delimited species of Saccharomyces sensu stricto. Antonie Leeuwenhoek 53:77-84.

49. Vezhinet, F., B. Blondin, and J. N. Hallet. 1990. Chromosomal DNA patterns and mitochondrial DNA polymorphism as tools for identification of enological strains of Saccharomyces cerevisiae. Appl. Microbiol. Biotechnol. 32:568571.

50. Winge, O., and C. Roberts. 1958. Yeast genetics, p. 123. In A. H. Cook (ed.), The chemistry and biology of yeast. Academic Press, New York.

51. Yamazaki, M., S. Goto, and K. Komagata. 1983. An electrophoretic comparison of the enzymes of Saccharomyces yeasts. J. Gen. Appl. Microbiol. 29:305-318.

52. Yarrow, D. 1984. Saccharomyces Meyen ex Reess, p. 379-395. In N. J. W. Kreger van Rij (ed.), The yeasts-a taxonomic study. Elsevier Science Publishing B.V., Amsterdam. 